\title{
Ensino de gramática e interação na perspectiva Bakhtiniana
}

DOI: http://dx.doi.org/10.21165/el.v49i3.2707

\section{Camila de Araújo Beraldo Ludovice'}

\section{Resumo}

Este trabalho tem por objetivo analisar as contribuições que podem ser dadas pelas reflexões de Mikhail Bakhtin (2010, 2013), em sua obra recentemente traduzida, para o ensino de gramática escolar, em especial, da análise sintática, associado ao ensino da estilística. Ele foi um filósofo preocupado com as relações entre o homem e suas interlocuções sociais por meio da linguagem, assim, as considerações filosóficas de Bakhtin podem fundamentar um trabalho produtivo com a gramática na escola, porque colocam a estilística e a interação como centro da preocupação pedagógica com a linguagem. Espera-se com esta pesquisa apresentar uma colaboração reflexiva e efetiva para o ensino de língua materna, pela integração do estudo da gramática à estilística e à perspectiva interacionista.

Palavras-chave: Bakhtin; gramática; estilística; interação; ensino.

1 Universidade de Franca (UNIFRAN), Franca, São Paulo, Brasil; camilaludovice@gmail.com; https://orcid.org/0000-0002-5998-7597 


\title{
Grammar, stylistics and interaction in Bakhtin
}

\begin{abstract}
This work aims to analyze Mikhail Bakhtin's $(2010,2013)$ recently translated work, focusing on his possible contributions to grammar education, particularly syntactic analysis associated with the teaching of stylistics. He was a philosopher concerned with the relationship between man and his social interlocutions through language. For this reason, Bakhtin's philosophical considerations can be the basis for productive work with grammar in school, since he places stylistics and interaction at the center of pedagogical concern with language. It is hoped that this research presents a reflexive and effective collaboration for first language teaching, integrating the study of grammar to stylistics and the interactionist perspective.
\end{abstract}

Keywords: Bakhtin; grammar; stylistic; interaction; teaching.

\section{Considerações iniciais}

O ensino de análise sintática constitui-se em um fator de desmotivação nas aulas de português, tanto para alunos, quanto para professores, conforme apontam Paschoal (2008) e Pernambuco (2007). Os alunos não aprendem a analisar sintaticamente um texto, porque não há metodologia adequada para o seu ensino (BAGNO, 2011) e, principalmente, porque a teoria gramatical que a sustenta é confusa, incoerente (PERINI, 2010), e não leva em consideração a necessidade de ela estar vinculada à estilística (BAKHTIN, 2013). Daí justificar-se esta análise do método bakhtiniano de ensino de gramática com apoio na estilística, apresentado no livro Questões de estilística no ensino da língua (BAKHTIN, 2013).

Nele, Bakhtin expõe o seu método de reelaboração das orações subordinadas sem conjunções, transformando-as em subordinadas com conjunções, para que os alunos possam perceber a riqueza estilística e dramática que existe nas subordinadas sem conjunção em relação às subordinadas com conjunções. Nestas, acentua-se o formalismo da língua escrita, enquanto naquelas predomina a expressividade e informalidade da língua viva. Bakhtin (2013) apresenta seu método de trabalho, com base em exemplos tirados de textos de autores consagrados da literatura russa e detalha os procedimentos didaticamente, para que os alunos consigam aprender a fazer opções diante de situações em que tenham de fazer uso das diferentes possibilidades de construção textual e discursiva que a língua coloca à disposição dos falantes. Com base nessas premissas, o objetivo deste trabalho é discutir, à luz da obra bakhtiniana recentemente traduzida e nas reflexões filosóficas sobre a linguagem efetuadas por esse pensador, o ensino de análise sintática e sua produtividade quando vinculado à estilística. 
O ensino de gramática, principalmente, a análise sintática, foi e continua sendo o grande desafio do ensino de português como língua materna (NEVES, 1994; PERNAMBUCO, 1993). Mesmo depois da entrada em vigor dos Parâmetros Curriculares Nacionais (1998), no contexto brasileiro, com orientações sobre o ensino de português no níveis fundamental e médio, pouco se alterou no ensino de gramática normativa (PASCHOAL, 2008).

É instigante a leitura dos textos de Bakhtin, bem como dos estudos que se fizeram e se fazem a respeito de sua obra em quase todos os países. Sempre se descobrem novas percepções e intuições deste surpreendente filósofo da linguagem, embora não tenha sido preocupação dele a elaboração de uma teoria pronta e acabada ou mesmo a organização de um conjunto de textos marcados pela unicidade ou por algum tipo de dogmatismo científico. O que fica patente em sua produção escrita é que ele procurou evitar a todo custo a compartimentação dos saberes, pois que lhe interessava, isso sim, estabelecer o diálogo entre os diferentes campos de estudos.

Podemos dizer que os estudos da linguagem, modernamente, em todas as suas implicações são influenciados de forma inescapável pelas reflexões desse notável pensador. Uma das importantes colaborações bakhtinianas para a interpretação de um texto refere-se ao fato de que o sentido se constitui não só pelos seus aspectos linguísticos, mas também, e principalmente, pela inextricável relação com o contexto extralinguístico, ou seja, pela relação que existe entre o texto e os fatores sociais, históricos, culturais e ideológicos de sua produção. Nenhum discurso é individual, segundo ele, já que se constrói por meio das relações entre seres sociais e todos os discursos sociais mantêm uma plena e permanente interação.

Com fundamento na premissa de interação discursiva (BAKHTIN; VOLÓCHINOV, 1997) há uma visão inovadora quanto à prática de produção textual na escola, baseada na interação comunicativa, embora na obra de Bakhtin (1995) não haja uma definição perceptível do conceito de texto. Ele intui e defende uma concepção de linguagem dialógica, isto é, toda palavra, enunciação, texto, possui um caráter de duplicidade, sendo fundamental a presença do outro. Cada enunciado é um elo na corrente complexamente organizada de outros enunciados.

\section{Bakhtin e suas reflexões}

Em suas reflexões, Bakhtin busca conhecer o homem de uma forma abrangente, na concretude de suas relações sociais, considerando as experiências acumuladas e a interação dessas experiências. Pode-se dizer que é através da fala do outro com quem se compartilha aprendizados, que se organizam as ideias e se procura tirar o melhor proveito delas, criando as próprias ideias. É a partir dessa interação que tudo se agiliza e que há a internalização de um saber construído por outro. Isso é aplicado em qualquer situação 
da vida; em uma sala de aula em que professor e aluno são sujeitos que encerram em si dialogicidade, ou seja, experiências individuais que interagem em um mesmo contexto social. O ouvinte na sua contribuição passiva não corresponde ao participante real da comunicação discursiva. Nas palavras de Bakhtin (1995, p. 274-275):

O discurso só pode existir de fato na forma de enunciações concretas de determinados falantes, sujeitos do discurso. O discurso sempre está fundido em forma de enunciado pertencente a um determinado sujeito do discurso, e fora dessa forma não pode existir. Por mais diferentes que sejam as enunciações pelo seu volume, pelo conteúdo, pela construção composicional, elas possuem como unidades da comunicação discursiva peculiaridades estruturais comuns, e antes de tudo absolutamente precisos. [...] O falante termina seu enunciado para passar a palavra ao outro ou dar lugar à sua compreensão altamente responsiva. O enunciado não é uma unidade convencional, mas uma unidade real, precisamente delimitada da alternância dos sujeitos do discurso ao qual termina com a transmissão da palavra ao outro. [...] Essa alternância dos sujeitos do discurso que cria limites precisos do enunciado nos diversos campos da atividade humana e da vida, dependendo das diversas funções da linguagem e das diferentes condições e situações de comunicação, é de natureza diferente e assume formas várias. [...] O diálogo é a forma clássica da comunicação discursiva. precisos do enunciado nos diversos campos da atividade humana e da vida, dependendo das diversas fun.

Considerando a oração como unidade da língua, há a necessidade de abordar sua distinção em face do enunciado como unidade de comunicação discursiva. A oração é um pensamento relativamente acabado, pois o falante faz uma pausa para passar em seguida ao seu pensamento subsequente. As pausas entre as enunciações não são de natureza gramatical, mas, sim, real; depois delas espera-se uma resposta ou uma compreensão responsiva de outro falante.

Segundo a visão bakhtiniana, é no fluxo da interação verbal que a palavra se concretiza como signo ideológico, que se transforma e ganha diferentes significados, de acordo com o contexto em que ela surge.

O que Bakhtin traz de novo aos professores que ensinam gramática é que estudar isoladamente a palavra na morfologia gramatical não tem sentido se não levar em conta que todas as palavras dialogam entre si e que uma palavra só tem existência com base em outras palavras. As unidades da língua estudadas pela gramática estão em estado latente para a elaboração dos enunciados com os quais interagimos na vida em sociedade. 
O princípio que norteia o ensino de gramática deve ser baseado no fato de que para viver e sobreviver as pessoas fazem enunciados e não análise morfológica ou sintática das frases e das palavras que as constituem. Não interessa ao locutor, quando produz seu enunciado, discutir o gênero e o número de uma palavra como lua, por exemplo. Saber que lua é um substantivo feminino e está no singular interessa apenas à construção gramatical da frase, mais importante do que isso é a percepção do potencial significativo dessa palavra.

A linguagem é mediadora do nosso acesso à realidade. O real se nos apresenta por meio da linguagem. Todo e qualquer objeto do mundo interior ou exterior é perpassado pelo discurso do outro. Para o filósofo russo, não se deve confundir fonética, morfologia e sintaxe com dialogismo. As unidades da língua por si sós não são dialógicas. As unidades reais de comunicação são os enunciados que se constituem com as unidades da língua.

Essa reflexão, assim posta, pode ser a indicação de um caminho seguro para o ensino de gramática, porque se exigirá uma vinculação total à estilística. Daí a relevância da publicação recente do livro Questões de estilística no ensino da língua (2013), tradução de Sheila Grillo e Ekaterina Volkova Americo. Trata-se de um texto que mesmo sem ser literário resistiu ao tempo e ainda mais, mostra que o ensino de gramática foi e continua sendo problemático na escola há muito tempo. Só mesmo um filósofo e também professor como Bakhtin seria capaz de tratar de problemas tão presentes no universo escolar e, ainda, propor uma metodologia para solucioná-los. Como se não bastasse, apresenta também o procedimento metodológico associado ao caráter dialógico da linguagem proposto pelo Círculo de Bakhtin em meados de 1920.

Essa obra demonstra a preocupação e atenção de Bakhtin pelo contexto escolar e pela crise no ensino de língua que já era presente naquela época e na Rússia, o mesmo que enfrentamos atualmente e há tempos no Brasil. Chama atenção a semelhança dos problemas apresentados pelos editores russos com os problemas enfrentados atualmente no ensino de língua materna, conforme a nota abaixo:

O problema da inter-relação entre gramática e estilística ligado à discussão do ensino escolar de língua russa foi abordado a partir do final do século XIX. A mudança nas concepções científico-metodológicas que fundamentavam o ensino de língua russa refletiu-se de forma imediata nos programas escolares: enquanto no programa dos anos 1921/22, aqui criticado por M. M. Bakhtin, defendia-se, de fato, a separação da gramática de outros aspectos da língua russa, por considerar que a gramática levava ao conhecimento e a estilística à prática; no programa dos anos de 1933/34, o estudo da língua russa era orientado acima de tudo para o domínio dos gêneros discursivos fundamentais, sendo que o estudo de gramática privada da sua hegemonia anterior era articulado aos estudos de estilística, de ortografia e de regras do bem falar. Entretanto, no programa dos anos 1938/39 e 
nos programas estereotipados dos anos posteriores, vigentes na escola à época em que MMB escreveu o artigo, ideias análogas adquiriram efetivamente um caráter superficial e contraditório assinalado aqui por M. M. Bakhtin. (BAKHTIN, 2013, p. 13).

E naquele momento Bakhtin já propunha a combinação de pesquisa, ensino e tentativas de caminhos metodológicos juntando teorias que enfrentam a língua em uso, tentando uma articulação entre sua concepção dialógica de linguagem e a prática para o ensino de aspectos gramaticais exigidos por um programa oficial. Isso comprova o caráter de professor e pesquisador que era Bakhtin.

Esse material foi publicado pela primeira vez em 1994, na revista Filologia Russa. De acordo com os relatos de Gogotichvíli (BAKHTIN, 2013, p. 45), "no arquivo constam dois manuscritos, o primeiro, escrito à mão por Bakhtin em várias folhas de caderno ordenadas e guardadas dentro de uma capa de caderno escolar, com o título 'M. M. Bakhtin. Questões de estilística nas aulas de língua russa no ensino médio' na capa.". Na primeira página do mesmo manuscrito o título é outro: "M. M. Bakhtin. Questões de estilística nas aulas de língua russa na $7^{a}$ série. O significado estilístico do período composto sem conjunções.". Tal manuscrito parece ser um rascunho inicial do artigo, escrito no período em que Bakhtin trabalhava como professor da escola ferroviária $n^{\circ} 39$ da estação Saviólovo da região de Kalínin e ao mesmo tempo na escola média no 14 de Kimri. A probabilidade maior é que Bakhtin tenha elaborado simultaneamente o plano da aula, ou um pouco antes da escrita do artigo.

Na visão de Gogotichvíli, em nota sobre o texto de Bakhtin (2013, p. 53),

[...] a originalidade do artigo consiste no fato de que, enquanto nos outros trabalhos o 'teste' da teoria dialógica era realizado basicamente nos diferentes meios de transmissão do discurso alheio, que, já por sua natureza, pressupõem relações dialógicas (enfatizava o estudo da linguagem das obras literárias nas quais a própria presença de vários personagens pressupõe, de antemão, a presença de relações dialógicas) - nesse caso o objeto da 'problematização atualizada' é o período composto sem conjunções, ou seja, uma construção linguística geral que tradicionalmente, não possui nenhuma ligação com o 'caráter dialógico' da construção semântica.

O artigo traz conceitos teóricos e reflexões bakhtinianas bem conhecidos atualmente, como relações dialógicas, mas nomeadas de forma diferente, como "elemento dramático" e "interação verbal". Então, mesmo para ensinar período composto e período subordinado, o filósofo e professor faz uso da teoria dialógica. Além disso, temos que considerar não apenas a conexão entre gramática e estilística, mas a interação entre professor e aluno 
na construção de conhecimento. Na verdade, esses dois aspectos são tomados como componentes e são contemplados tanto pela teoria quanto pela metodologia proposta por Bakhtin.

As leituras que fazemos diuturnamente da obra de Bakhtin levam-nos a descobrir que o ensino de gramática na escola brasileira pode ganhar novo alento, se o professor perceber que a palavra, a frase, a oração, o período sintático podem e devem ser ensinados de forma integrada à estilística. Daí a importância do lançamento entre nós do livro.

\section{A análise sintática e a estilística no ensino, na perspectiva de Bakhtin}

Deacordo com Bakhtin (2013, p. 23): "as formas gramaticais não podem ser estudadas sem que se leve em conta seu significado estilístico. Quando isolada dos aspectos semânticos e estilísticos da língua, a gramática inevitavelmente degenera em escolasticismo". O verbo "poder" traz ao artigo uma marca do pensamento pedagógico do professor Bakhtin: para ele é indispensável a integração gramática e estilística. O que acontecia lá com o ensino de gramática é o mesmo que ocorre aqui entre nós.

Para Bakhtin (2013, p. 23): "Na prática, muito raramente o professor dá e sabe dar explicações estilísticas para as formas gramaticais estudadas. Às vezes, ele até aborda a estilística nas aulas de literatura (aliás, muito pouco e de modo superficial), mas o conteúdo das aulas de língua materna é a gramática pura". Não se deve culpar o professor pelo ensino predominantemente gramatical que ele conduz: a sua formação é esta mesma. Apesar dos avanços da linguística, ele não se capacitou para trabalhar de forma diferente do que vem sendo feito no ensino de português há séculos no Brasil.

Quando o professor Bakhtin escreve sobre linguagem própria, ele imprime ao artigo a ideologia de sua atividade docente: quanto mais meios de expressão a escola puder ajudar os alunos a adquirir, mais eles serão capazes de atuar como cidadãos ativos na vida social. Na perspectiva de Bakhtin (2013, p. 28): "Sem a abordagem estilística, o estudo da sintaxe não enriquece a linguagem dos alunos e, privado de qualquer tipo de significado criativo, não Ihes ajuda a criar uma linguagem própria; ele os ensina apenas a analisar a linguagem alheia já criada e pronta. Entretanto, isso já é escolástico".

E mais ainda:

Depois de revelar o enorme significado das formas de subordinação sem conjunção na nossa língua e de atentar às suas vantagens diante das formas correspondentes com conjunções, é necessário, porém, mostrar aos alunos a legitimidade e a necessidade da existência na língua dessas últimas formas também; é preciso não apenas apontar a importância da subordinação com 
conjunção na linguagem prática e científica, mas também a impossibilidade de evitá-la na literatura de ficção. Os alunos devem entender que as formas de subordinação sem conjunção não podem ser utilizadas sempre. (BAKHTIN, 2013, p. 39).

Bakhtin estabelece uma adequada distinção entre a fala viva e a literatura. Não se exclui com essa diferenciação a necessidade de a escola preocupar-se também em conduzir os alunos para a intimidade com os textos literários.

Como professor comprometido, de fato, com o ensino e a avaliação do progresso do aluno em busca de ampliação de suas habilidades linguísticas no uso da língua viva, Bakhtin (2013, p. 39) fornece pistas para o trabalho de avaliação do professor:

Depois, junto com os alunos, analisaremos os resultados de todo o trabalho estilístico que foi feito. O professor verifica em que medida o objetivo do trabalho foi alcançado: ele conseguiu ensinar aos alunos o gosto e o amor à subordinação sem conjunção? Os alunos conseguiram realmente apreciar o caráter expressivo e a vivacidade dessas formas? Se esse objetivo for atingido, resta ao professor apenas levar os estudantes a empregarem essas formas em sua linguagem oral e escrita.

Como um idealista, ele utiliza dois substantivos abstratos muito apreciados por uma certa pedagogia do afeto: gosto e amor, referindo-se à subordinação sem conjunção. Só não se pode taxá-lo de idealista porque há conteúdo teórico denso por trás dessa prática pedagógica de integração da gramática com a estilística.

Didaticamente, Bakhtin (2013, p. 39-40) relata o modo como realizou a prática pedagógica:

Realizei essa prática da seguinte maneira. Em primeiro lugar, fazíamos uma série de exercícios especiais no decorrer dos quais formávamos diversas variantes de períodos compostos com e sem conjunções de acordo com temas previamente dados, ponderando cuidadosamente a conveniência e a utilidade estilística de uma ou outra forma. Depois, ao verificar os trabalhos feitos em casa e em sala de aula, eu chamava a atenção para todos os casos em que foi conveniente a substituição da subordinação com conjunção pela sem conjunção e fazia uma modificação estilística consequente nos cadernos dos alunos. Durante a análise dos trabalhos na sala de aula, todos esses períodos eram lidos em voz alta e discutidos, sendo que às vezes os "autores" não concordavam com a minha correção e surgiam discussões animadas e interessantes. É claro, havia casos em que alguns alunos entusiasmavam-se demais com as formas sem conjunção e nem sempre as utilizavam de modo adequado. 
Os passos seguidos por Bakhtin, nesse trabalho, servem de guia e modelo a todos os professores interessados em uma prática como essa de condução do aluno para a aquisição de habilidade no uso da língua viva e criativa para a sua comunicação cotidiana.

O que acontece com um professor quando lê o livro de Bakhtin é que ele é levado a fazer comparações com o seu trabalho pedagógico com o ensino de análise sintática. O método bakhtiniano de ensinar análise sintática com base na estilística revela seu cuidado com o ensino e uma atitude responsiva ao acontecimento do seu existir. Fica claro o caminho: as técnicas e exercícios de sala de aula derivam de uma metodologia que é fundamentada em uma teoria que tem na base uma ideologia. Quanto mais meios de expressão o professor puder propiciar aos alunos, mais condições eles terão de responder ao ato de existir.

\section{0 texto do aluno como ponto de partida}

Diante do trabalho bakhtiniano apresentado até aqui, propusemo-nos a apresentar princípios para uma proposta de ensino de uso da língua viva por alunos de $6^{\circ}$ ano do ensino fundamental brasileiro.

Um procedimento indispensável nessa prática de trabalho com o texto em sala de aula é conhecer o aluno em termos de estágio de língua em que se encontra, o seu meio ambiente familiar, as suas expectativas em relação à escola, os seus interesses e gostos. E o melhor caminho para essa verdadeira diagnose é a criação de condições adequadas para a fala e para a produção de textos na modalidade escrita da língua. O professor deverá provocar a fala do aluno para que ele se expresse sobre o seu mundo. Esse processo deve durar o tempo necessário para que todos os alunos da classe falem e que a fala de cada um seja respeitada e ouvida pelos outros.

O passo seguinte será a estimulação para o texto escrito sem qualquer tipo de exigência ou promessa de avaliação. Esse momento é importante para ir retirando do aluno o verdadeiro trauma que todos vão adquirindo desde a escola primária de que quando escrevem o fazem para a correção e atribuição de notas pelo professor. Esse papel de censor e de avaliador deve ser esquecido pelo professor. Não é pelas correções de ordem gramatical ou pelas notas que ele atribui que o aluno vai aprender a produzir textos bem estruturados e com sentido.

Tão logo os alunos tenham escrito este primeiro texto, o professor deverá estimular cada um para que leia para os demais o texto que acabou de escrever. É uma excelente oportunidade de eles irem perdendo a inibição natural que todos experimentam ao terem que mostrar o texto que produzem e, para o professor, uma possibilidade de verificar a concepção que cada aluno tem da modalidade escrita da língua em relação à modalidade oral. 
É preciso que o professor tenha conhecimentos seguros a respeito dos processos que acontecem na leitura e na redação para que sua interferência seja adequada no sentido de conduzir da melhor forma o aluno ao domínio da habilidade de produção de textos na modalidade escrita.

Nessa primeira etapa da proposta, estamos levando em conta os três importantes elementos do processo de leitura e escrita: o aluno e seu universo linguístico, o processo da fala e da escrita e o professor com a concepção que ele tem da tarefa de ler e escrever e com o seu projeto de ensino. Quando falamos do universo linguístico do aluno, estamos fazendo referência às experiências que ele já tem com a língua, à variante da língua que ele domina e ao seu modo de encarar as modalidades oral e escrita da língua.

Não temos dúvidas de que a chegada à produção do texto escrito é bem mais complexa do que a aprendizagem da fala, mas, da mesma forma como aprendeu a ouvir e a falar, o aluno poderá aprender a ler e a escrever textos, desde que esse processo seja bem conduzido pelo professor.

Os primeiros textos escritos pelos alunos de $6^{\circ}$ anos, sujeitos da pesquisa feita por nós, serviram para nos dar um referencial importante para a elaboração do nosso projeto de ensino a ser desenvolvido durante o ano letivo. Pedimos primeiramente que eles escrevessem sobre algum fato ocorrido com eles, quando eram ainda muito pequenos, e depois contassem tudo sobre a vida fora da escola, sobre a rua em que moravam, os vizinhos, os amigos, os brinquedos e sua convivência com os pais e irmãos dentro de casa. Um mesmo texto com dois temas.

Observemos alguns dos textos produzidos por eles:

(1) "Quando eu era pequena meu pai chegou do serviço, meu pai não gosta que minha mãe fuma e aí meu pai pegou minha mãe fumando e começaram a brigar e aí foi uma grande briga. Eu não gosto de ver meus pais brigando gosto de ver minha casa em paz e amor". [...]

"Eu gosto muito dos meus vizinhos não tenho queixa deles nunca foram mal para mim. Só que tem uma vizinha minha que briga muito comigo não sei por quê. Tem muitas amigas todas gostam de mim e eu gosto muito delas tenho uma amiga que ela é muito boa para mim. Gosto muito de brincar de basquete, vôlei, queimada, pique esconde, etc."

(G. M. -11 anos)

Podemos notar aqui que o tema proposto possibilita que o aluno se expresse de uma maneira livre e descomprometida com as questões gramaticais. Ele se sente confortável 
para simplesmente expressar seus sentimentos, angústias e incômodos. Mesmo em se tratando de redação escolar, o compromisso da aluna parece ser com a interação possibilitada pelo uso da língua e não pelo rigor gramatical que impera com relação ao uso dessa língua na escola. De acordo com Bakhtin (2013), a expressividade da língua se constrói no momento de interação e é exatamente isso que a aluna faz, ela se expressa e interage com o professor por meio da língua no seu texto escrito que, na verdade, reproduz sua fala. Aqui a aluna consegue expressar seu descontentamento com a briga dos pais e seu incômodo com o fato de apenas uma vizinha não gostar muito dela e brigar constantemente, fatos esses que realmente parecem incomodá-la no dado momento.

(2) "A minha rua e legal e se chama Luis Pires da Cruz. Ela é limpa e meus vizinhos são todos leguais. Os meus amigos são sinceros e legais, eles topam qualquer parada. Mes brinquedos são bonecas da estrela todas pequenas uma chama Gisele, Emília, Agarradinho, fofolete dum ovo, etc."

"A minha vida longe dos meus pais são difíceis mas eu tenho que enfrentar o mundo do jeito que ele é".

"Eu trabalho mas no meu emprego do que na minha casa".

"Então eu curto muito pouco a vida mas de vez em quando eu vou em casa ver meus pais".

"Mas tem vez que eu poso no meu emprego".

"Porque tenho que comprar roupa ou talvez dou o dinheiro em casa para minha mãe".

(A. R. P. -12 anos)

Esse texto, embora apresente, do ponto de vista da gramática normativa, também chamada de tradicional, muitas inadequações, é uma autêntica amostra da língua viva e coloquial e expressa a "vivacidade e a expressividade do discurso" (BAKHTIN, 2015, p. 39), as ideias de seu autor e mantém viva e intensa a interação com seu leitor. Quem lê percebe que é uma transcrição da oralidade, mas percebe também a dificuldade enfrentada por esse aluno que precisa trabalhar e para isso fica longe de casa e dos pais. Em seu relato, nota-se o ponto de vista otimista com relação à rua que "é legal", mas que ele quase não consegue aproveitar pela necessidade precoce do trabalho. Esse texto, inicialmente, não apresenta uso de conjunções, o autor faz uso de frases justapostas. Mas quando ele começa a expressar a dificuldade enfrentada por viver longe dos pais, ele faz uso repetido da conjunção coordenativa "mas", tentando explicar e justificar que, embora difícil, faz-se necessário enfrentar o mundo e as dificuldades da vida. Não faz parte do repertório dos alunos de $6^{\circ}$ ano o uso de conjunções subordinativas. No último excerto é que ela utiliza a conjunção "porque", com tom explicativo para esclarecer o motivo de ter que dormir no emprego. 
(3) "A minha mãe disse que quando eu nasci meu irmão ficou de mal com minha mãe, porque eu nasci mulher".

$[\ldots]$

"A minha rua é muito boa. Os meus vizinhos são muitos bons. Eu tenho muitos amigos. Eles são muito legais. Eu gosto muito dos meus amigos. Eu gosto muito de brincar com meus amigos. Eu tenho muitas bonecas. Eu tenho muitos brinquedos, mas eu não gosto de brincar. Eu só brinco de escola. Eu sou a professora. Eu gosto muito de escrever com giz".

(E. A. S. -11 anos)

O texto 3 não faz uso de nenhuma conjunção subordinativa, o autor apresenta as informações em frases justapostas. Na visão de Bakhtin, ao analisar os textos de seus alunos na língua russa, esse recurso torna o texto muito mais expressivo, pois não fica preso a uma seleção rígida do léxico. Mesmo que de forma simples e muito próxima da oralidade, nota-se que o texto apresenta uma progressão temática interessante. A autora chega ao pico da interação expondo seu gosto por brincar de escola e ser a professora. Sua linguagem é viva, expressiva, muito própria da criança em fase de desenvolvimento psicológico que atesta sua subjetividade e centralidade do eu. Não precisa de nenhuma explicação (ou conjunção subordinativa) para entender seu pendor pela profissão em forma de brincadeira.

(4) "Quando era pequeno minha mãe me bateu porque estava comendo açucar. E eu fiquei muito triste porque estava comendo açucar. Eu fiquei muito triste e eu fuji de casa. Eu saí corendo pelo asfalto e o carro quase me atrupelou. Eu fiquei com medo mais quis fugir de casa".

$[\ldots]$

"A rua da minha casa é muito triste não tem luz é tudo escuro e não da para eu brincar".

"Os meus vizinhos são tudo ruim para mim eu não gosto deles".

"Meus amigos quase não tenho nenhum".

"Não tenho com quem brincar".

"Minha vida é muito triste".

(D. A. S. -14 anos)

Esse texto, embora com problemas no aspecto gramatical, consegue na interação com o leitor expressar suas angústias e tristezas. O autor, desde o início, mesmo repetindo expressões e cometendo erros de ortografia, pontuação e concordância consegue expressar a sua revolta e o seu medo quando apanhou da mãe por um motivo banal. A tristeza continua expressa no decorrer do texto quando conta da escuridão da rua, da dificuldade para brincar, dos vizinhos ruins, da solidão. Mesmo sem nenhuma conjunção 
subordinativa no final do texto, podemos acompanhar sua progressão para o amarguradoe expressivo desfecho da conclusão: "minha vida é muito triste". Concordando com Bakhtin (2013), podemos refletir sobre a ausência de conjunção nesse exemplo e constatar que a falta do uso deixa mais fortemente marcada a expressão e o tom de melancolia da afırmação final. O autor, em seu uso coloquial da língua, conseguiu expressar totalmente seu desgosto com a vida e sua experiência no mundo.

Essa amostragem de quatro textos escritos pelos alunos revela uma série de aspectos que precisam ser analisados com atenção.

O aprendiz não encara a tarefa de escrever a partir de sua experiência pessoal como sendo difícil, mesmo porque a hipótese que ele elabora nessa fase é de que a escrita é a transcrição gráfica da fala. Não experimenta ainda nenhuma coerção sobre o seu ato de produção de textos escritos, não está apegado a nenhum modelo e o processo de interlocução é estabelecido primeiramente com uma espécie de outro-eu, que filtra as suas ideias, e só depois ele se dirige a um outro interlocutor que pode ser uma pessoa do seu próprio meio ou o professor. Lendo-se os textos com atenção, dá para perceber que o aluno não parece preocupado com a possível avaliação do professor, tanto é que não se preocupa em reler o texto à procura de possíveis falhas. Escrever, para ele, é falar através da palavra escrita.

Esse tipo de texto confessional é interessante porque permite detectar globalmente o relacionamento do aluno com o mundo através da linguagem que ele usa. O autor do texto demonstra tal como ele é com sua visão de mundo. O importante nessa fase é o enfoque sobre o aluno que produz o texto e não sobre o texto produzido. A partir do conhecimento que se tem do aprendiz com base no texto que ele produz é que se deve traçar um projeto de ensino adequado às necessidades, interesses, gostos, visando a uma seleção e organização de material de ensino que conduzam o aluno a travar intimidade com textos escritos e daí levá-lo à aquisição da realidade de produção de textos. Não estamos querendo afirmar que o aluno que lê fatalmente saberá produzir textos, mas estamos propondo a leitura também como uma receita adequada para a escrita.

A tarefa do professor é a de ir mediando a chegada do aluno ao texto escrito, mesmo porque esse processo acontece por etapas tal como para aquisição da fala ou mesmo da alfabetização. O sujeito da aprendizagem vai construindo ele mesmo as suas hipóteses a respeito do que seja a fala, bem como quando está sendo alfabetizado, ele vai construindo o seu conhecimento por etapas. O que importa ao trabalho do professor num primeiro momento é levar o aluno a aprender a pensar o que seja a modalidade escrita da língua mais próxima do que Bakhtin chama de língua da vida viva ou, simplesmente, língua viva. 


\section{Considerações finais}

A metodologia de trabalho de Bakhtin com o ensino de gramática vinculada à estilística e as suas reflexões e do seu Círculo podem fundamentar um trabalho produtivo com a análise sintática na escola, porque colocam a interação e o uso da língua viva como centro da preocupação pedagógica com a linguagem e, assim, indicam a necessidade de reflexão sobre a normatividade gramatical vir a ser função da interlocução, do uso real da língua viva e não de um saber sobre a linguagem e a língua.

Bakhtin traz de novo aos professores que ensinam gramática o fato de que as formas gramaticais não podem e não devem ser ensinadas separadas de sua forma estilística. Pois, quando isolada dos aspectos semânticos e estilísticos, sua função fica extremamente vinculada à escola e não à língua viva, em funcionamento.

Isso acontece porque, na prática, raramente o professor dá explicações estilísticas nas aulas e quando faz, vincula o estilo apenas à literatura, de maneira escassa e muito superficial. E o estudo da sintaxe sem a abordagem da estilística não enriquece o aprendizado dos alunos, não desenvolve nem enriquece a linguagem desses estudantes.

Assim, o ensino tradicional de língua materna não amplia a habilidade linguística dos alunos, pois se concentra em atividades mecânicas e cansativas de análise da sintaxe. $\mathrm{Na}$ prática pedagógica, falta ao professor ensinar o aluno a dominar os recursos linguísticos para aplicá-los na interação social em busca de dar respostas ao seu existir.

\section{REFERÊNCIAS}

BAGNO, M. Gramática pedagógica do português brasileiro. São Paulo: Parábola, 2011.

BAKHTIN, M. M.; VOLÓCHINOV, V. N. A interação verbal. In: BAKHTIN, M. M.; VOLÓCHINOV, V. N. Marxismo e filosofia da linguagem. Tradução Michel Lahud e Yara Frateschi Veira. 8. ed. São Paulo: Hucitec, 1997.

BAKHTIN, M. M. Questões de estilística no ensino da língua. Tradução, posfácio e notas de Sheila Grillo e Ekaterina Vólkova Américo; apresentação de Beth Brait; org. e notas da ed. russa de Serguei Botcharov e Liudmila Gogotichvíli. São Paulo: Editora 34, 2013.

NEVES, M. H. M. Gramática na escola. São Paulo: Contexto, 1994.

PASCHOAL, M. M. S. Contribuições da linguística para o ensino da gramática. 2008. Dissertação (Mestrado em Linguística) - Universidade de Franca, Franca, 2008. 
PERINI, M. A. Gramática do português brasileiro. São Paulo: Parábola: 2010.

PERNAMBUCO, J. Análise do trabalho do professor: a prescrição, a realização e a representação. In: CARMELINO, A. C.; PERNAMBUCO, J.; FERREIRA, L. A. (org.). Nos caminhos do texto: atos de leitura. Franca: Unifran, 2007 (Coleção Mestrado em Linguística, 2).

PERNAMBUCO, J. A redação escolar: análise dos efeitos da escolaridade. 1993. Tese (Doutorado em Educação) - Faculdade de Educação, Universidade de São Paulo, São Paulo, 1993.

PERNAMBUCO, J. A aprendizagem de língua portuguesa na 5a série do ensino de primeiro grau: uma experiência e princípios para uma proposta de ensino. 1986. Dissertação (Mestrado em Linguística) - Faculdade de Ciências e Letras, Universidade Estadual Paulista "Júlio de Mesquita Filho", Araraquara, 1986. 